\title{
Improving health outcomes with better patient understanding and education
}

This article was published in the following Dove Press journal:

Risk Management and Healthcare Policy

12 October 2010

Number of times this article has been viewed

\section{Robert John Adams}

The Health Observatory, The Queen Elizabeth Hospital Campus, The University of Adelaide, Woodville, South Australia, Australia
Correspondence: Robert John Adams The Health Observatory, The University of Adelaide, The Queen Elizabeth Hospital Campus, Woodville SA 50I I, Australia Tel +61882226740

Fax +618 82226042

Email robert.adams@adelaide.edu.au
Abstract: A central plank of health care reform is an expanded role for educated consumers interacting with responsive health care teams. However, for individuals to realize the benefits of health education also requires a high level of engagement. Population studies have documented a gap between expectations and the actual performance of behaviours related to participation in health care and prevention. Interventions to improve self-care have shown improvements in self-efficacy, patient satisfaction, coping skills, and perceptions of social support. Significant clinical benefits have been seen from trials of self-management or lifestyle interventions across conditions such as diabetes, coronary heart disease, heart failure and rheumatoid arthritis. However, the focus of many studies has been on short-term outcomes rather that long term effects. There is also some evidence that participation in patient education programs is not spread evenly across socio economic groups. This review considers three other issues that may be important in increasing the public health impact of patient education. The first is health literacy, which is the capacity to seek, understand and act on health information. Although health literacy involves an individual's competencies, the health system has a primary responsibility in setting the parameters of the health interaction and the style, content and mode of information. Secondly, much patient education work has focused on factors such as attitudes and beliefs. That small changes in physical environments can have large effects on behavior and can be utilized in self-management and chronic disease research. Choice architecture involves reconfiguring the context or physical environment in a way that makes it more likely that people will choose certain behaviours. Thirdly, better means of evaluating the impact of programs on public health is needed. The Reach, Effectiveness, Adoption, Implementation and Maintenance (RE-AIM) framework has been promoted as one such potential approach.

Keywords: self-management, health literacy, patient education, behavioral economics, program evaluation

Chronic disease self-management and preventive health programs mainly focus on promoting informed lifestyle choices, risk-factor modification, and active patient self-management of chronic diseases. ${ }^{1}$ Such a process relies heavily on better information and communication practices. The logic of health reform that emphasizes preventive and enhanced primary models of care is an expanded role for informed, active consumers interacting with responsive health care teams. ${ }^{1}$ Most observers agree that this central role demands improved education and understanding of health behavior and chronic disease management. However, for individuals to realize the benefits of health education also requires a high level of participation and engagement, ie, action or behavior related to health.

In the context of burgeoning current health care costs and alarming projections of future costs, the potential community and individual payoff is immense. It was estimated 
in 1993 that half of the annual mortality toll in the US was premature. ${ }^{2}$ Significantly, it was shown that these deaths could be deferred with the modification of just 10 behaviors, such as tobacco use, diet, physical activity, alcohol consumption, and others, including exposure to microbial agents, exposure to toxic agents, use of firearms, sexual behavior, motor vehicle crashes, and illicit use of drugs. Nearly $80 \%$ of premature deaths were attributed to just three behaviors in the list - tobacco use, dietary pattern, and physical activity level. ${ }^{2}$ More recent evidence from a cohort study of over 23,000 German adults followed for 8 years showed that four behaviors accounted for a $78 \%$ variance in the apparent risk of a serious chronic disease. ${ }^{3}$ Again, smoking, diet, and physical activity are implicated. As one of the four (maintenance of a $\mathrm{BMI}<30$ ) is not a behavior per se, but rather largely a byproduct of two other behaviors already on the list (eating well and being active), the "difference between life and death and health and illness is substantially dictated by just three behaviors". "For those with all four "healthy behaviors" compared with those with none, the hazard ratio for diabetes, myocardial infarction, stroke, or cancer was 0.22 [95\% confidence interval (CI): $0.17-0.28]$. The presence of just one healthy behavior as compared with none cut the chronic disease risk by half (adjusted HR, 0.51; 95\% CI: 0.43-0.60). ${ }^{3}$

Numerous factors go into influencing behavior, and a review of the social determinants of health is beyond the scope of this review. However, to give an example of the power of social factors such as inadequate access to health care, educational disparities, and poverty, consider the analysis of Woolf et $\mathrm{al}^{5}$ who examined death rates among adults with inadequate education in the US. The authors used education-associated excess mortality as a proxy for this web of sociological, economic, and biological variables..$^{5}$ They applied indirect standardization techniques to estimate the maximum number of deaths averted between 1996 and 2002 that is attributable to medical advances and the number of deaths that would have been averted if mortality rates among adults with lesser education had been the same as those among college-educated adults. The authors concluded that, "in comparison with the gain from medical advances, 8 times as many deaths would be averted if mortality rates among adults with an inadequate education were the same as those among individuals at higher education levels". ${ }^{5}$ It is with this overwhelming statistic in mind that this review turns to the more limited and specific issues relating to patient or health education, usually from within the health care system.

There is a large and growing literature documenting the gap between expectations and the actual performance of behaviors related to participation in health care and prevention. Review topics in the Cochrane Library indicate that most interventions to increase consumer engagement include promoting patient medication compliance, chronic disease self-management, and traditional health promotion behaviors around smoking, diet, and exercise. Efforts to enhance clinical encounters have largely focused on encouraging patients to ask questions through coaching or written encouragement. Another focus has been on individuals to increase self-care, improve health literacy, and assist with clinical decision making. ${ }^{6}$ In a recent review, Coulter and Ellins ${ }^{7}$ found few trials or systematic reviews describing interventions to support navigating the health care system or promoting ease of access to care.

This article reviews some of the evidence concerning the effectiveness of some of the strategies to improve care, particularly of chronic conditions, before considering some of the issues in patient education and consumer engagement and participation that can impact on these strategies.

\section{Specific conditions or problems}

The most consistent positive outcome of interventions to improve self care has been improvement in self-efficacy, ${ }^{8}$ an important element of self-management. Most studies of selfmanagement programs have reported improvements in patient satisfaction, coping skills, and perceptions of social support, although the focus has tended to be on short-term outcomes rather than on long-term effects..$^{9-39}$ For these outcomes, the results of studies on self-management programs in diabetes have been more mixed..$^{40-47}$ Diabetes education alone appears ineffective in improving metabolic control. ${ }^{48}$ Most, but not all, reviews on diabetes self-management interventions have shown improvements in glucose control, as well as improvement in quality of life. ${ }^{14,18,40-67}$ Randomized controlled trials (RCTs) of self-management or lifestyle interventions for diabetes that examine cost benefit have variously shown reductions in diabetes incidence, ${ }^{68,69}$ improvements in co-morbid depression, ${ }^{70}$ and clinical benefits, ${ }^{71-73}$ although others have shown no clinical benefits. ${ }^{74,75}$ Although studies from administrative databases ${ }^{49}$ and studies other than RCTs have indicated reduced costs for those enrolled in self-management programs, RCT evidence in diabetes management or prevention has not consistently supported this finding. ${ }^{76}$ Of note is that administrative data suggest that participation in diabetes education is not spread evenly across socioeconomic groups, with one study showing that participants were younger, more were female, located in more affluent areas, at lower clinical risk, and at higher adherence 
to diabetes standards of care. ${ }^{49}$ Asthma self-management programs have produced varied results in terms of improving symptoms and quality of life, with generally better results for programs that include regular practitioner review than for education alone interventions..$^{38,39,77-83}$ There is not much evidence that self-management programs have a clinically significant impact on health status in chronic obstructive pulmonary disease (COPD), although hospital admissions may be reduced. ${ }^{84-87}$

Numerous interventions to improve adherence with medication regimens have been studied. Few have been successful in increasing medication use over the longer term. Almost all the interventions that were effective for long-term care were complex, with multiple combinations of interventions. These have included combinations of more convenient care, information, reminders, self-monitoring, reinforcement, counseling, family therapy, psychological therapy, crisis intervention, manual telephone follow-up, and supportive care. However, the improvements in adherence and treatment outcomes have been generally modest. ${ }^{39,68,69,88-90}$

In patients with rheumatoid arthritis, patient education has an immediate, albeit small, beneficial effect for disability, joint counts, patient global assessment, psychological status, and depression. ${ }^{91}$ However, one systematic review found no benefit over longer follow-up times of between 3 and 14 months. ${ }^{92}$ Others have found modest improvements in ER and obstructive pulmonary disease visits but not in other clinical outcomes with self-management programs. ${ }^{93}$ Similarly, self-management programs for epilepsy may improve knowledge about epilepsy and reduce seizure frequency. However, the evidence is limited and has tended to include higher proportions of people with partial seizures than would be expected in a community sample, making it difficult to make conclusions. ${ }^{94}$ There is strong evidence that exercise therapy for multiple sclerosis has a positive effect on exercise tolerance and mobility. ${ }^{95}$ However, selfmanagement research in multiple sclerosis is limited, particularly with regard to comprehensive programs. ${ }^{96}$ In people with coronary artery disease, education and stress management programs have been shown to improve outcomes. ${ }^{28,97}$ Heart failure management programs that include initiating self-management interventions also demonstrate a positive effect on outcomes such as hospital readmissions, quality of life, and mortality. However, a recent review found that improvements are not always significant and noted methodological shortcomings, limiting the quality of the published evidence. The authors called for further research to determine independent effects of self-management interventions and different combinations of interventions on clinical and patient-reported outcomes. ${ }^{98}$

A systematic review concluded that "the evidence is overwhelming that physical activity and diet can reduce the risk of developing numerous chronic diseases, including coronary artery disease, hypertension, diabetes, and the metabolic syndrome". ${ }^{99}$ Few studies have examined the isolated effect of training on the prevention of diabetes in patients with impaired glucose tolerance, but there is good evidence for a beneficial effect of combined physical training and dietary modification. ${ }^{100}$ Walker et al ${ }^{100}$ examined the evidence for diet and exercise lifestyle changes in the prevention of diabetes. They found a number of studies across different populations, which showed that lifestyle change may reduce the incidence of type 2 diabetes by $28 \%-59 \%$, with the effects seen many years after the intervention. ${ }^{73,101-106}$ Regular exercise appeared necessary to maintain weight control and risk reduction. A comprehensive systematic review has found that there is strong evidence for the benefits of exercise in improving clinical outcomes in metabolic disorders such as diabetes and hypertension; coronary heart disease (CHD) and heart failure; depression; fibromyalgia and knee osteoarthritis. ${ }^{107}$ The evidence is less strong for clinically significant improvements in asthma, COPD, or other forms of arthritis. Exercise training improves exercise capacity in patients with chronic renal failure treated with hemodialysis. ${ }^{108,109}$ The benefits in quality of life are often most notable in those with the lowest baseline levels. ${ }^{110}$

\section{Types of interventions}

Interventions to improve coordination of care between different parts of the health care system have shown mixed results. ${ }^{111}$ A Cochrane review concluded that there was no evidence to support the widespread introduction of shared care. ${ }^{12}$ Attempts to integrate care of depression in patients with medical conditions have been generally positive with regard to depression care, but the effects on medical care are less well established. ${ }^{113}$

Computer-based programs for people with chronic disease may combine health information with online peer support, decision support, or help with behavior change. Such programs have been shown to increase knowledge, feelings of social support, and some clinical outcomes among users. ${ }^{31}$ There is evidence that home-based information technology interventions can reduce health care costs. ${ }^{114}$ Computer-based programs can also be useful for behavioral risk reduction in areas such as smoking and diet. ${ }^{115}$ However, as the authors of a Cochrane Review noted, much work is still needed to 
determine the best type and best way to deliver interactive computer programs and to establish how they have their effects for different groups of people with chronic illness. ${ }^{31}$

Decision aids aim to assist individuals in making decisions, where the balance between benefits and harms are not absolutely clear or where there is a substantial degree of uncertainty about the scientific evidence. A systematic review found that decision aids improved knowledge and accuracy of risk perception and increased people's involvement and degree of comfort ("decisional conflict") with decision making. The effect on actual decisions is variable, although it appears that decision aids reduce the use of discretionary surgery without apparent adverse effects on health outcomes or satisfaction. Again, the effects show substantial variations across studies, suggesting that factors not studied may be influencing the processes and outcomes. ${ }^{116}$

\section{Information provision alone}

Several studies have shown that telling people about adverse effects of their medications did not affect their use of the medications. However, not providing full information about medications has been reported to contribute to lower adherence ${ }^{117}$ and may increase medical errors. ${ }^{118}$ Patient information insets in pill packets do not help to improve adherence, ${ }^{94,119}$ but specific reminder packaging may improve adherence to long-term medication. ${ }^{94,120}$ Providing people with risk information on CHD increases the accuracy of risk perception. A recent systematic review found that interventions that provide information on a repeated basis have shown small significant reductions in predicted CHD risk (absolute differences, $-0.2 \%$ to $-2 \%$ over 10 years in studies using risk estimates derived from Framingham equations). However, providing risk information only at one time point is ineffective. ${ }^{121}$

\section{Implications}

A number of commentators have provided us with approaches to develop more effective ways to address chronic illness. ${ }^{122,123}$ However, as one author has asserted, "the evidence of success is slim". ${ }^{124}$ Although, recently, progress has certainly been made, the evidence for improvement in clinical outcomes, as distinct from some processes of care or the behavior of clinicians, is far from convincing. In particular, the evidence for dramatic improvements in public health is unclear. ${ }^{3}$ The less than overwhelming results of interventions to improve selfcare, education, and understanding requires us to consider what additional ingredients or alternative approaches might be of benefit. This review will consider two conceptual areas and one evaluation approach that may be used to add value to patient education, engagement, and self-management.

\section{Health literacy}

An emerging area of research in the field of consumer education and engagement is health literacy, ie, the capacity to seek, understand, and act on health information. ${ }^{125}$ There is a clear presumption in the literature that low literacy and numeracy means health communication is poorly understood, leading to inadequate self-management and perceptions of health responsibility and inappropriate health care utilization. ${ }^{126}$ Health literacy is also cast as a social determinant of health (as is functional literacy) both for individuals and for populations due to its impact on socioeconomic status, employment, and ability to access services. ${ }^{126}$ It is known that self-management practices ${ }^{127}$ and self-management skills ${ }^{128}$ vary by patient's level of health literacy. Functional health literacy (FHL) has been identified as a predictor of selfefficacy ${ }^{8}$ in diabetes and HIV-self care. ${ }^{129,130}$ An independent association between health literacy and self-efficacy has also been found regarding participation in, and to seek information about, cancer screening programs. ${ }^{131}$ There is also evidence that low FHL is linked with poor health outcomes. ${ }^{132,133}$ The scope of the problem is dramatic, with $45 \%$ of adults at risk for limited health literacy, ${ }^{134,135}$ which indicates that many people with adequate general literacy may have difficulty applying this in specific health contexts. ${ }^{125,136}$ Numeracy, particularly regarding statistics, is another important related concept. ${ }^{137}$ A recent study found that, of a sample of American and German adults, $64.5 \%$ and $68.5 \%$, respectively, could answer nine simple questions related to statistical numeracy, with wide disparities across social class seen especially in the US. ${ }^{138}$ Only $24 \%$ of the Americans were able to express 1 in 1,000 as a percentage. ${ }^{138}$ A Swiss Government analysis indicated that $3 \%-5 \%$ of all health care spending can be attributed to low health literacy. ${ }^{139}$

Despite all this, few studies have specifically taken health literacy into account for delivering an intervention program, by attempting to take low health literacy into account as a risk factor to be managed. A number of interventions have attempted to specifically tailoring programs to individuals with low health literacy, with some success in improving outcomes in conditions such as diabetes. ${ }^{140}$ A relatively small number of studies have aimed to improve health literacy with a variety of complex interventions and then examined the impact on health behavior and outcomes. Clement et al ${ }^{141}$ have recently reviewed these studies. The authors noted that most trials reported improved outcomes, but only 8 of the 
15 trials included in their review measured direct clinical outcomes. Knowledge and self-efficacy were the class of outcome most likely to improve. A variety of strategies were used in a number of different combinations across different health conditions, including care management; simplifying language in written materials; use of pictorial information, videos, and audiotapes; specifically checking for understanding, spacing information, and training professionals in communication techniques. ${ }^{141}$

There is some evidence suggesting ways in which health literacy impacts on education interventions. Evidence shows that adults with limited health literacy are less likely to ask questions to clinicians. ${ }^{142}$ People with poorer reading skills describe the density of text in a decision aid in a colorectal screening program as "intimidating and frightening". ${ }^{143}$ Individuals with less than university education are less likely to classify themselves as information seekers. ${ }^{144}$ Limited health literacy is also problematic once information has been accessed. Men with lower health literacy skills were found to be 4 times more likely to refuse the offer for colorectal cancer screening, even if it was recommended by their physician. ${ }^{145}$ Lower literacy skills were associated with considerably less accuracy in portion-size estimation when participants were asked to serve a single serving of various foods. ${ }^{146}$

One of the difficulties in applying the notion of health literacy to interventions has been lack of consensus over the definition of the concept. A person's skills in literacy and numeracy as they relate to health have been described as "FHL". ${ }^{125}$ However, while the associations between health literacy, health-related knowledge, and attitudes are significant, previous studies have found that these associations only partially account for people's actual performance. As Peerson and Saunders note, ${ }^{147}$ "although knowledge is often considered a prerequisite for change in attitudes and behaviors that lead to better health, that relationship is not always direct, positive, linear, or even necessarily present". Rubinelli et al ${ }^{148}$ contend that, "critical health literacy reflects the individual's capacity to contextualize health knowledge for his or her own good health to decide on a certain action after a full appraisal of what that specific action means for them in their own world". Because FHL only partly accounts for health-related behavior, ${ }^{136}$ the definition of health literacy has been expanded to include factors that can influence health decisions and behavior. These encompass the ability to find, understand, evaluate, and select information from different sources and then put this to use in decision making in that specific context. ${ }^{125,149-151}$ There is, however, little or no empirical research evaluating this wider concept. ${ }^{147}$ Furthermore, these expanded definitions do not appear to consider the possibility that someone may possess and understand health information without using it in healthpromoting ways. ${ }^{147}$ It is axiomatic that "to effectively access, understand, and apply received health messages, individuals must be motivated to receive and process the information". ${ }^{152}$ It may therefore be useful to distinguish between possessing information; understanding it; and the inclination and ability to act on it appropriately. ${ }^{147}$

One suggestion has been to screen for "patient activation" 153,154 or readiness to better determine the likelihood of engagement by individuals and of success in achieving better understanding and behavior change. ${ }^{155}$ The value of establishing "psychotypes" would be analogous to "personalized medicine" in determining genotypes for targeting therapeutic pharmaceutical interventions. As a means of better targeting scarce resources, this approach deserves further consideration. However, the risk is that by focusing on the patient, this approach tends to let the health care system off the hook in its responsibility to give people real control and choice about whether, how, where, and when they use health services, supported by access to evidence-based information that facilitates informed choices, as a platform for creating an agile and self-improving health system. ${ }^{136}$ It is all too easy to label someone as "not ready" or "disengaged" when the interaction with the health care system is confusing, inconsistent, or involves labyrinthine system navigation.

\section{The responsibility of the health care system}

Consequently, before considering the patient's readiness, the health care system has a responsibility to proactively enable more accessible interactions and environments that promote health and well-being. ${ }^{156}$ Health literacy is primarily the responsibility of health systems, given that it is the health system that determines the parameters of health interaction, including the physical setting, available time, communication style, content and mode(s) of information provided, attitudes to the provision of information, and definitions of concepts such as sound health decision making and compliance. ${ }^{157}$ It is only then that consideration should be given to the preferences of patients regarding communication styles, content, and media.

There is a wealth of literature that identifies a number of characteristics, indicating better health professional communication behaviors, in isolation and in combination. ${ }^{158-160}$ 
Behaviors that clinicians can use to ameliorate the potential risks associated with limited health literacy include avoiding the use of medical jargon, showing interest in questions, explaining forms, and confirming understanding through techniques such as teach-back and use of visual aids. ${ }^{161}$ However, the evidence that training in communication skills for clinicians leads to improvements in health outcomes is mixed. ${ }^{67,162-}$ ${ }^{167}$ Similarly, the evidence that patient-centered consultations can improve health outcomes is limited. ${ }^{166,168,169}$

However, few of these interventions have specifically considered the preferences of people for how they receive information and interact with the health care system. This issue is compounded when the skills and competencies of people are not specifically taken into consideration. Specially targeted interventions can help to increase knowledge and understanding in people with low health literacy and seem to improve outcomes, although the number of trials is limited. ${ }^{170}$ Educational packages, which may include videotapes and multimedia programs, specifically developed for low-literacy populations can help to improve knowledge, while brief, group-based didactic teaching seems to be of limited value. . $^{18,158,171,172}$

Ultimately though, as Kane ${ }^{155}$ asserts, "disease management can work only when there is a receptive patient partner". Kane suggests that Prochaska's ${ }^{173,174}$ readiness assessment for prevention offers one model for looking at the question of patient activation or motivation. ${ }^{153}$ An alternative conceptualization may be understood as a process of health competency, starting with recognition that an issue or problem is relevant to an individual, accepting that this issue exists and requires decisions to be made and some form of action be taken, seeking out and critically evaluating information, undertaking actions with regard to this issue in the light of knowledge gained, and then personalising the issue by monitoring the effects or outcomes over time. Such a conceptualization involves personal skills and competencies, attitudes, motivation, and the inclination to act with regard to health and recognizes that these may be context-specific to situations, health conditions, and modes of social and/or clinical interaction. ${ }^{134}$ As a personal asset, health literacy so defined acknowledges individuals' social and cultural contexts and calls for engagement in social action for health and participation in altered social norms that can enable action on the social determinants of health. ${ }^{126}$ It suggests an expanded role for the health system: patient education, improving the parameters of the health care interaction and facilitating navigation through an often labyrinthine health system, and fostering development in schools, adult learning, and community development programs. ${ }^{126}$
Hibbard and Mahoney have shown that low levels of activation are associated with negative effect, particularly with regard to their health. ${ }^{154}$ These authors suggest that this implies people who are struggling in managing their health recognize their failure and feel badly about themselves. ${ }^{175}$ The implications of their results are that reversing this situation involves encouraging behaviors that produce small successes, such as reading a food label. Tailoring support and education in this context requires taking the level of activation into account, as well as their skills and competencies in health literacy. Too much information can overwhelm individuals, especially if large changes in lifestyle are demanded, and this can potentially increase negative emotions and perpetuate passivity or avoidance. As the authors point out, "not understanding a patient's activation level may mean that a routine office visit interaction could be harmful to them". ${ }^{175}$

Effective health education would then need to consider the health literacy and activation of individuals. Communication can be tailored to take into account the preferences of patients for type or media, along with frequency of contact and the skills or competencies of individuals. Some people may prefer in-person meetings, others may use the telephone, some prefer video conferencing, and still others are contented with a text message. ${ }^{155}$ In this way, the health literacy of individuals and families can be matched by a health care system that is health literate "aware". Furthermore, the cost of interactions could vary by type, either via a market signal or within a public framework that provides some incentive for clinicians to participate. ${ }^{176}$ Such considerations will need to be included into new initiatives such as the Australian Government's recently announced diabetes care program in primary care. ${ }^{177}$ If general practitioners are to be held accountable for the results of diabetes management, then some means of both assessing patients activation/motivation and enhancing it needs to be part of the program. Clinicians are unable to reliably identify the health literacy levels of their patients. ${ }^{178}$ Measuring health literacy in every patient is impractical, and so some health literacy experts advocate that clinicians should perform assessments on a sample of their practice patients to learn the prevalence of limited health literacy in their practice. ${ }^{179}$ This may in turn stimulate changes to communication practices in clinical encounters.

While integrating health literacy and patient activation into the development of interventions to improve health care have intuitive appeal, there is little empirical work to demonstrate efficacy. As mentioned earlier, despite commentator's enthusiasm on a variety of ways to improve the care and management of chronic illness, success has not always been 
overwhelming when tested in clinical trials. ${ }^{122-124}$ Therefore, before widespread changes can be recommended, considerably more research is required.

\section{Behavioral economics}

Behavioral economics has gained increasing attention in public policy recently, ${ }^{180}$ possibly driven by several influential books such as Nudge. ${ }^{181}$ This has led to a greater appreciation of the need to take the context, settings, and physical environment into account when developing behavior change interventions. The focus of much patient education and self-management work has been on personal factors such as attitudes and beliefs. The evidence showing often small changes in physical environments can have large effects on behavior could lead to a rich new stream of research on patient behavior and effective communication strategies. Another relevant concept is that of "choice architecture", where reconfiguring the context or physical environment in a way that makes it more likely that people will choose a behavior that is better for them and better for other people is achieved while fully preserving their freedom to choose alternative behaviors. ${ }^{181}$ Although examples exist on the concept being used in influencing choices around insurance or medication coverage, there has been less work on how choice architecture could be used in disease management programs.

As discussed earlier, motivation is regarded as a crucial factor affecting behavior. However, even highly motivated individuals often have difficulty in making decisions in the short term that favor their long-term interests. ${ }^{182}$ To see if medication adherence could be enhanced using ideas derived from behavioral economics, Volpp et al ${ }^{183}$ conducted a small uncontrolled trial in stroke patients using incentives from the behavioral economics literature, including small, frequent rewards; offering a small chance at a big reward; and the desire people have to avoid regret at missing a payoff. The objective was to increase compliance with warfarin as assessed objectively with an electronic pillbox device. Patients were entered into two daily lotteries. Participants had either a 1 in 5 or a 1 in 10 chance of winning a $\$ 10$ prize and a 1 in 100 chance of winning a $\$ 100$ prize, producing an expected value each day of $\$ 3$ or $\$ 5$. Incorrect tablet usage led to disqualification from the lotteries, and lottery winners who were noncompliant were told that their noncompliance would mean no payout. In the first pilot group, they found that incorrect pill or noncompliance decreased from a historic mean of $22 \%$ to $2.3 \%$. The percent of out-of-range INRs decreased from
$35.0 \%$ to $12.2 \%$ with the intervention, before increasing to $42 \%$ post-intervention. In the second pilot, percentage of incorrect pills dropped to $1.6 \%$. The same group also found in a study of similar design that a lottery with an expected daily value of $\$ 3$ led to significant weight loss compared with a control group. ${ }^{184}$ As the authors suggest, "A lottery (or other reward system that provides frequent positive reinforcement) can be thought of as a way to help patients to internalize long-term benefits so that they make decisions in the short term that favor their long-term interests". ${ }^{183}$ Although such small-scale, non-RCT evidence is not yet compelling, it provides encouragement for further more rigorous trials to be conducted, where ideas from outside the health field may be adapted to improve behavioral interventions and health outcomes. In particular, we need to know how behavioral effects can be maintained for longer term and whether habits can be internalized if the incentive is provided for a longer period.

\section{Evaluating program impact}

Most of the evidence discussed earlier provides estimates of the efficacy in clinical trials of various programs in chronic disease. Evaluation of the effectiveness of programs and their impact on public health is more difficult to establish. Indeed the criteria for judging whether a program has produced a significant public health impact is not broadly agreed upon. Experience indicates that many programs of proven efficacy fail when implemented in real-world settings. Some authors have advocated for a broader research and evaluation perspective than the narrow focus of the clinical trial that can use standard metrics across multiple indicators to judge programs. The Reach, Effectiveness, Adoption, Implementation and Maintenance (RE-AIM) framework has been promoted as one such approach. ${ }^{185}$ This approach recommends addressing the different elements of a program: (a) reach, or who is willing to participate; (b) effectiveness, the impact of the program; (c) adoption, the settings and staff who take part in the program; (d) implementation, how skillfully the program is delivered; and (e) maintenance, to what extent individual participants and the organizations involved sustain their involvement (see http://www.re-aim.org/). These dimensions can be examined individually or as combined impact indices. Interestingly, as one group observed, these combined indices tend to use only two dimensions because historically few studies provide data on more than two RE-AIM dimensions. ${ }^{186}$ Comparison of diabetes programs using multiple RE-AIM metrics has demonstrated the difficulties that exist in making choices about which program 
is the "best" of various available choices. Comparing two diabetes self-management programs, Glasgow et al ${ }^{187}$ found that while one program performed better on reach and consistency across different populations, another was more likely to be adopted and adopted more consistently by staff. These authors concluded that when decision makers are weighing up which direction they should go, "programs should be chosen based on the results that one's organization values most". ${ }^{187}$

\section{Disclosure}

The author reports no conflicts of interest in this work.

\section{References}

1. Wagner EH, Austin BT, Davis C, Hindmarsh M, Schaefer J, Bonomi A. Improving chronic illness care: translating evidence into action. Health Aff. 2001;20:64-78.

2. McGinnis JM, Foege WH. Actual causes of death in the United States. JAMA. 1993;270:2207-2212.

3. Ford ES, Bergmann MM, Kröger J, Schienkiewitz A, Weikert C, Boeing $\mathrm{H}$. Healthy living is the best revenge: findings from the European Prospective Investigation into Cancer and Nutrition-Potsdam Study. Arch Intern Med. 2009;169:1355-1362.

4. Katz DL. Life and death, knowledge and power: why knowing what matters is not what's the matter. Arch Intern Med. 2009;169:1362-1363.

5. Woolf SH, Johnson RE, Phillips RL Jr, Philipsen M. Giving everyone the health of the educated: an examination of whether social change would save more lives than medical advances. Am J Public Health. 2007;97:679-683.

6. Coulter A, Ellins J. Effectiveness of strategies for informing, educating, and involving patients. BMJ. 2007;335:24-27.

7. Coulter A, Ellins J. Patient-focused Interventions: A Review of the Evidence. London, UK: The Health Foundation, 2006.

8. Bandura A. Self-efficacy: toward a unifying theory of behavioural change. Psychol Rev. 1977;84:191-215.

9. Barlow J, Wright C, Sheasby J, Turner A, Hainsworth J. Self-management approaches for people with chronic conditions: a review. Patient Educ Couns. 2002;48:177-187.

10. Astin JA, Beckner W, Soeken K, Hochberg MC, Berman B. Psychological interventions for rheumatoid arthritis: a meta-analysis of randomized controlled trials. Arthritis Rheum. 2002;47:291-302.

11. Bradley PM, Lindsay B. Care delivery and self-management strategies for adults with epilepsy. Cochrane Database Syst Rev. 2008;(1):CD006244.

12. Campbell HS, Phaneuf MR, Deane K. Cancer peer support programs do they work? Patient Educ Couns. 2004;55:3-15.

13. Cooper H, Booth K, Fear S, Gill G. Chronic disease patient education: lessons from meta-analyses. Patient Educ Couns. 2001;44:107-117.

14. Coster S, Gulliford MC, Seed PT, Powrie JK, Swaminathan R. Monitoring blood glucose control in diabetes mellitus: a systematic review. Health Technol Assess. 2000;4:i-93.

15. de Ridder D, Schreurs K. Developing interventions for chronically ill patients: is coping a helpful concept? Clin Psychol Rev. 2001;21:205-240

16. Desplenter FAM, Simoens S, Laekeman G. The impact of informing psychiatric patients about their medication: a systematic review. Pharm World Sci. 2006;28:329-341.

17. Dolder CR, Lacro JP, Leckband S, Jeste DV. Interventions to improve antipsychotic medication adherence: review of recent literature. J Clin Psychopharmacol. 2003;23:389-399.
18. Eakin EG, Bull SS, Glasgow RE, Mason M. Reaching those most in need: self-management interventions in disadvantaged populations. Diabetes/Metabolism Res Rev. 2002;18:26-35.

19. Eysenbach $\mathrm{G}$. The impact of the Internet on cancer outcomes. CA Cancer J Clin. 2003;53:356-371.

20. Smith J, Forster A, House A, Knapp P, Wright JJ, Young J. Information provision for stroke patients and their caregivers. Cochrane Database Syst Rev. 2008;(2):CD001919.

21. Foster G, Taylor SJC,Eldridge SE, Ramsay J, Griffiths CJ. Self-management education programmes by lay leaders for people with chronic conditions. Cochrane Database Syst Rev. 2007;(4):CD005108.

22. Gaston CM, Mitchell G. Information giving and decision-making in patients with advanced cancer: a systematic review. Soc Sci Med. 2005;61:2252-2264.

23. Griffiths K, Christensen H. Review of randomised controlled trials of internet interventions for mental disorders and related conditions. Clin Psychol. 2006;10:16-29.

24. Gysels M, Higginson IJ. Interactive technologies and videotapes for patient education in cancer care: systematic review and meta-analysis of randomised trials. Support Care Cancer. 2007;15:7-20.

25. Hoey LM, Ieropoli SC, White VM, Jefford M. Systematic review of peer-support programs for people with cancer. Patient Educ Couns. 2008;70:315-337.

26. Jaber R, Braksmajer A, Trilling JS. Group visits: a qualitative review of current research. J Am Board Fam Med. 2006;19:276-290.

27. Johnson WD, Diaz RM, Flanders WD, et al. Behavioral interventions to reduce risk for sexual transmission of HIV among men who have sex with men. Cochrane Database Syst Rev. 2008;3: CD001230.

28. Jolly K, Taylor R, Lip GYH, et al. The Birmingham Rehabilitation Uptake Maximisation Study (BRUM). Home-based compared with hospital-based cardiac rehabilitation in a multi-ethnic population: cost-effectiveness and patient adherence. Health Technol Assess. 2007;11:1-118.

29. Macvean ML, White VM, Sanson-Fisher R. One-to-one volunteer support programs for people with cancer: a review of the literature. Patient Educ Couns. 2008;70:10-24.

30. McPherson CJ, Higginson IJ, Hearn J. Effective methods of giving information in cancer: a systematic literature review of randomized controlled trials. J Public Health Med. 2001;23:227-234.

31. Murray E, Burns J, See Tai S, Lai R, Nazareth I. Interactive health communication applications for people with chronic disease. Cochrane Database Syst Rev. 2005;4:CD004274.

32. Niedermann K, Fransen J, Knols R, Uebelhart D. Gap between short- and long-term effects of patient education in rheumatoid arthritis patients: a systematic review. Arthritis Rheum. 2004;51:388-398.

33. Pitkethly M, MacGillivray S, Ryan R. Recordings or summaries of consultations for people with cancer. Cochrane Database Syst Rev. 2008;3:CD001539.

34. Rehse B, Pukrop R. Effects of psychosocial interventions on quality of life in adult cancer patients: meta analysis of 37 published controlled outcome studies. Patient Educ Couns. 2003;50:179-186.

35. Savelkoul M, de Witte L, Post M. Stimulating active coping in patients with rheumatic diseases: a systematic review of controlled group intervention studies. Patient Educ Couns. 2003;50:133-143.

36. Scott JT, Prictor M, Harmsen M, et al. Interventions for improving communication with children and adolescents about a family member's cancer. Cochrane Database Syst Rev. 2003;4:CD004511.

37. Ranmal R, Prictor M, Scott JT. Interventions for improving communication with children and adolescents about their cancer. Cochrane Database Syst Rev. 2008;4:CD002969.

38. Toelle B, Ram FSF. Written individualised management plans for asthma in children and adults. Cochrane Database Syst Rev. 2004;(1):CD002171.

39. Wolf F, Guevara JP, Grum CM, Clark NM, Cates CJ. Educational interventions for asthma in children. Cochrane Database Syst Rev. 2002;4:CD000326. 
40. Deakin T, McShane CE, Cade JE, Williams RDR. Group based training for self-management strategies in people with type 2 diabetes mellitus. Cochrane Database Syst Rev. 2005;2:CD003417.

41. Farmer A, Gibson OJ, Tarassenko L, Neil A. A systematic review of telemedicine interventions to support blood glucose self-monitoring in diabetes. Diabetic Med. 2005;22:1372-1378.

42. Norris SL, Engelgau MM, Narayan KM. Effectiveness of self management training in type 2 diabetes: a systematic review of randomized controlled trials. Diabetes Care. 2001;24:561-587.

43. Norris SL, Nichols PJ, Caspersen CJ, et al. Increasing diabetes selfmanagement education in community settings. A systematic review. Am J Prev Med. 2002;22:39-66.

44. van Dam HA, van der Horst FG, Knoops L, Ryckman RM, Crebolder HF, van den Borne BH. Social support in diabetes: a systematic review of controlled intervention studies. Patient Educ Couns. 2005;59:1-12.

45. Welschen LMC, Bloemendal E, Nijpels G, et al. Self-monitoring of blood glucose in patients with type 2 diabetes mellitus who are not using insulin. Cochrane Database Syst Rev. 2005;2:CD005060.

46. Zhang XP, Norris SL, Chowdhury FM, Gregg EW, Zhang P. The effects of interventions on health-related quality of life among persons with diabetes - a systematic review. Med Care. 2007;45:820-834.

47. Cochran J, Conn VS. Meta-analysis of quality of life outcomes following diabetes self-management training. Diabetes Educ. 2008;34:815-823.

48. Duke SA, Colagiuri S, Colagiuri R. Individual patient education for people with type 2 diabetes mellitus. Cochrane Database Syst Rev. 2009; 1:CD005268.

49. Duncan I, Birkmeyer C, Coughlin S, Li Q, Sherr D, Boren S. Assessing the value of diabetes education. Diabetes Educ. 2009;35:752-760.

50. Corabian P, Harstall C. Patient Diabetes Education in the Management of Adult Type 2 Diabetes. Health Technology Assessment 23: Series A. Alberta, Canada: Alberta Heritage Foundation for Medical Research, 2001.

51. Ellis SE, SperoffT, Dittus RS, Brown A, Pichert JW, Elasy TA. Diabetes patient education: a meta-analysis and meta-regression. Patient Educ Couns. 2004;52:97-105.

52. Fan L, Sidani S. Effectiveness of diabetes self-management education intervention elements: a meta-analysis. Can J Diabetes. 2009;33:18-26.

53. Gary TL, Genkinger JM, Guallar E, Peyrot M, Brancati FL. Metaanalysis of randomized educational and behavioral interventions in type 2 diabetes. Diabetes Educ. 2003;29:488-501.

54. Hampson SE, Skinner TC, Hart J, et al. Effects of educational and psychosocial interventions for adolescents with diabetes mellitus: a systematic review. Health Technol Assess. 2001;5:1-79.

55. Hawthorne K, Robles Y, Cannings-John R, Edwards AGK. Culturally appropriate health education for type 2 diabetes mellitus in ethnic minority groups. Cochrane Database Syst Rev. 2008;3:CD006424.

56. Jansen JP. Self-monitoring of glucose in type 2 diabetes mellitus: a Bayesian meta-analysis of direct and indirect comparisons. Curr Med Res Opin. 2006;22:671-681.

57. Loveman E, Cave C, Green C, Royle P, Dunn N, Waugh N. The clinical and cost-effectiveness of patient education models for diabetes: a systematic review and economic evaluation. Health Technol Assess. 2003;7:iii, 1-190.

58. Loveman E, Frampton GK, Clegg AJ. The clinical effectiveness of diabetes education models for type 2 diabetes: a systematic review. Health Technol Assess. 2008;1-116, iii.

59. National Institute for Clinical Excellence. Guidance on the Use of Patient Education Models for Diabetes. London, UK National Institute for Clinical Excellence; 2003.

60. Norris SL, Lau J, Smith SJ, Schmid CH, Engelgau MM. Self-management education for adults with type 2 diabetes: a meta-analysis of the effect on glycemic control. Diabetes Care. 2002;25:1159-1171.

61. Norris SL, Zhang X, Avenell A, et al. Long-term effectiveness of lifestyle and behavioral weight loss interventions in adults with type 2 diabetes: a meta-analysis. Am J Med. 2004;117:762-774.
62. Sarkisian CA, Brown AF, Norris KC, Wintz RL, Mangione CM. A systematic review of diabetes self-care interventions for older, African American, or Latino adults. Diabetes Educ. 2003;29:467-479.

63. Steed L, Cooke D, Newman S. A systematic review of psychosocial outcomes following education, self-management and psychological interventions in diabetes mellitus. Patient Educ Couns. 2003;51:5-15.

64. Valk GD, Kriegsman DMW, Assendelft WJJ. Patient education for preventing diabetic foot ulceration. Cochrane Database Syst Rev. 2001;4:CD001488.

65. van Dam H, van der Horst F, van den Borne B, Ryckman R, Crebolder H. Provider-patient interaction in diabetes care: effects on patient self-care and outcomes. A systematic review. Patient Educ Couns. 2003;51:17-28.

66. Vermeire EIJJ, Wens J, van Royen P, BiotY, Hearnshaw H, Lindenmeyer A. Interventions for improving adherence to treatment recommendations in people with type 2 diabetes mellitus. Cochrane Database Syst Rev. 2005;2:CD003638.

67. Wens J, Vermeire E, Hearnshaw H, Lindenmeyer A, Biot Y, van Royen P. Educational interventions aiming at improving adherence to treatment recommendations in type 2 diabetes. A sub-analysis of a systematic review of randomised controlled trials. Diabetes Res Clin Pract. 2008;79:377-388.

68. Eddy DM, Schlessinger L, Kahn R. Clinical outcomes and costeffectiveness of strategies for managing people at high risk for diabetes. Ann Intern Med. 2005;143:251-264.

69. Knowler WC, Barrett-Connor E, Fowler SE, et al; for Diabetes Prevention Program Research Group. Reduction in the incidence of type 2 diabetes with lifestyle intervention or metformin. $N$ Engl J Med. 2002;346:393-403.

70. Katon W, Unutzer J, Fan M, et al. Cost effectiveness and net benefit of enhanced treatment of depression for older adults with diabetes and depression. Diabetes Care. 2006;29:265-270.

71. Herman WH, Brandle M, Zhang P, et al; for Diabetes Prevention Program Research Group. Costs associated with the primary prevention of type 2 diabetes mellitus in the diabetes prevention program. Diabetes Care. 2003;26:36-47.

72. Diabetes Prevention Program Research Group. Within-trial cost-effectiveness of lifestyle intervention or metformin for the primary prevention of type 2 diabetes. Diabetes Care. 2003;26: 2518-2523.

73. Testa MA, Simonson DC. Health economic benefits and quality of life during improved glycemic control in patients with type 2 diabetes mellitus: a randomized, controlled, double-blind trial. JAMA. 1998;280:1490-1496.

74. Chase HP, Pearson JA, Wightman C, Roberts MD, Oderberg AD, Garg SK. Modem transmission of glucose values reduces the costs and need for clinic visits. Diabetes Care. 2003;26:1475-1479.

75. de Weerdt, Visser AP, Kok GJ, van derVeen EA. Randomized controlled multicentre evaluation of an education programme for insulin-treated diabetic patients: effects on metabolic control, quality of life and cost of therapy. Diabetes Med. 1991;8:338-345.

76. Boren SA, Fitzner KA, Panhalkar PS, Specker JE. Costs and benefits associated with diabetes education: a review of the literature. Diabetes Educ. 2009;35:72-96.

77. Bhogal S, Zemek R, Ducharme FM. Written action plans for asthma in children. Cochrane Database Syst Rev. 2006;3:CD005306.

78. Coffman JM, Cabana MD, Yelin EH. Do school-based asthma education programs improve self-management and health outcomes? Pediatrics. 2009;124:729-742.

79. Gibson PG, Powell H, Coughlan J, et al. Limited (information only) patient education programs for adults with asthma. Cochrane Database Syst Rev. 2002;2:CD001005.

80. Gibson PG, Powell H, Coughlan J, et al. Self-management education and regular practitioner review for adults with asthma. Cochrane Database Syst Rev. 2003;1:CD001117.

81. Powell H, Gibson PG. Options for self-management education for adults with asthma. Cochrane Database Syst Rev. 2002;3:CD004107. 
82. Smith JR, Mugford M, Holland R, Noble M, Harrison B. Psychoeducational interventions for adults with severe or difficult asthma: a systematic review. J Asthma. 2007;44:219-241.

83. Tapp S, Lasserson TJ, Rowe BH. Education interventions for adults who attend the emergency room for acute asthma. Cochrane Database Syst Rev. 2007;3:CD003000.

84. Adams SG, Smith PK, Allan PF, Anzueto A, Pugh JA, Cornell JE. Systematic review of the chronic care model in chronic obstructive pulmonary disease prevention and management. Arch Intern Med. 2007; 167:551-561.

85. Effing T, Monninkhof EM, van der Valk PD, et al. Self-management education for patients with chronic obstructive pulmonary disease. Cochrane Database Syst Rev. 2007;4:CD002990.

86. Monninkhof EM, van der Valk PD, van der Palen J, et al. Self-management education for chronic obstructive pulmonary disease. Cochrane Database Syst Rev. 2003;1:CD002990.

87. Turnock AC, Walters EH, Walters JAE, Wood-Baker R. Action plans for chronic obstructive pulmonary disease. Cochrane Database Syst Rev. 2005;4:CD005074.

88. Haynes RB, Ackloo E, Sahota N, McDonald HP, Yao X. Interventions for enhancing medication adherence. Cochrane Database Syst Rev. 2008;2:CD000011.

89. Williams A, Manias E, Walker R. Interventions to improve medication adherence in people with multiple chronic conditions: a systematic review. JAdv Nurs. 2008;63:132-143.

90. Vergouwen AC, Bakker A, Katon WJ, Verheij TJ, Koerselman F. Improving adherence to antidepressants: a systematic review of interventions. J Clin Psychiatry. 2003;64:1415-1420.

91. Warsi A, LaValley MP, Wang PS, Avorn J, Solomon DH. Arthritis self-management education programs: a meta-analysis of the effect on pain and disability. Arthritis Rheum. 2003;48:2207-2213.

92. Riemsma RP, Kirwan JR, Taal E, Rasker HJJ. Patient education for adults with rheumatoid arthritis. Cochrane Database Syst Rev. 2003;2:CD003688

93. Lorig KR, Ritter P, Stewart AL, et al. Chronic disease self-management program: 2-year health status and health care utilization outcomes. Med Care. 2001;39:1217-1223.

94. Shaw EJ, Stokes T, Camosso-Stefinovic J, Baker R, Baker GA, Jacoby A. Self-management education for adults with epilepsy. Cochrane Database Syst Rev. 2007;2:CD004723.

95. Rietberg MB, Brooks D, Uitdehaag BMJ, Kwakkel G. Exercise therapy for multiple sclerosis. Cochrane Database Syst Rev. 2005; 1:CD003980.

96. Fraser R, Johnson E, Ehde D, Bishop M. Patient Self-management in Multiple Sclerosis. White Paper Series. Hackensack, NJ: Consortium of Multiple Sclerosis Centers, 2009.

97. Dusseldorp E, van Elderen T, Maes S, Meulman J, Kraaij V. A metaanalysis of psychoeducational programs for coronary heart disease patients. Health Psychol. 1999;18:506-519.

98. Ditewig JB, Blok H, Havers J, van Veenendaal H. Effectiveness of self-management interventions on mortality, hospital readmissions, chronic heart failure hospitalization rate and quality of life in patients with chronic heart failure: a systematic review. Patient Educ Couns. 2010;78:297-315.

99. Roberts CK, Barnard RJ. Effects of exercise and diet on chronic disease. J Appl Physiol. 2005;98:3-30.

100. Walker KZ, O’Dea K, Gomez M, Girgis S, Colagiuri R. Diet and exercise in the prevention of diabetes. J Hum Nutr Diet. 2010;23:344-352.

101. Pan XR, Li GW, Hu YH, et al. Effects of diet and exercise in preventing NIDDM in people with impaired glucose tolerance. The Da Qing IGT and Diabetes Study. Diabetes Care. 1997;20: 537-544.

102. Li G, Zhang P, Wang J, et al. The long-term effect of lifestyle interventions to prevent diabetes in the China Da Qing Diabetes Prevention Study: a 20-year follow-up study. Lancet. 2008;371: 1783-1789.
103. Knowler WC, Fowler SE, Hamman RF, et al; for Diabetes Prevention Program Research Group. 10-year follow-up of diabetes incidence and weight loss in the Diabetes Prevention Program Outcomes Study. Lancet. 2009;374:1677-1686.

104. Lindstrom J, Ilanne-Parikka P, Peltonen M, Aunola S, et al. Sustained reduction in the incidence of type 2 diabetes by lifestyle intervention: follow-up of the Finnish Diabetes Prevention Study. Lancet. 2006;368:1673-1679.

105. Tuomilehto J, Lindstrom J, Eriksson JG, et al; for Finnish Diabetes Prevention Study Group. Prevention of type 2 diabetes mellitus by changes in lifestyle among subjects with impaired glucose tolerance. N Engl J Med. 2001;344:1343-1350.

106. Ramachandran A, Snehalatha C, Mary S, Mukesh B, Bhaskar AD, Vijay V; for Indian Diabetes Prevention Programme (IDPP). The Indian Diabetes Prevention Programme shows that lifestyle modification and metformin prevent type 2 diabetes in Asian Indian subjects with impaired glucose tolerance (IDPP-1). Diabetologia. 2006;49: 289-297.

107. Pedersen BK, Saltin B. Evidence for prescribing exercise as therapy in chronic disease. Scand J Med Sci Sports. 2006;16 Suppl 1:3-63.

108. Cheema BS, Singh MA. Exercise training in patients receiving maintenance hemodialysis: a systematic review of clinical trials. Am J Nephrol. 2005;25:352-364.

109. Painter P, Johanson KL. Improving physical functioning: time to become a part of the routine care. Am J Kidney Dis. 2006;48:167-170.

110. Painter PL, Carlson S, Carey SM, Myll J. Low functioning patients improve with exercise training. Am J Kidney Dis. 2000;36:600-608.

111. Brand CA, Jones CT, Lowe AJ, et al. A transitional care service for elderly chronic disease patients at risk of readmission. Aust Health Rev. 2004;28:275-284.

112. Smith SM, Allwright S, O'Dowd T. Effectiveness of shared care across the interface between primary and specialty care in chronic disease management. Cochrane Database Syst Rev. 2007;3:CD004910.

113. Butler M, Kane RL, McAlpine D, et al. Integration of Mental Health/ Substance Abuse and Primary Care. Rockville, MD: Agency for Healthcare Research and Quality, 2008. Contract No. 290-02-0009; Evidence Report/Technology Assessment No. 173, AHRQ Publication No. 09-E003.

114. Gaikwad R, Warren J. The role of home-based information and communications technology interventions in chronic disease management: a systematic literature review. Health Informatics $J$. 2009;15:122-146.

115. Portnoy DB, Scott-Sheldon LAJ, Johnson BT, Carey MP. Computerdelivered interventions for health promotion and behavioral risk reduction: a meta-analysis of 75 randomized controlled trials, 1988-2007. Prev Med. 2008;47:3-16.

116. Connor AM, Bennett CL, Stacey D, et al. Decision aids for people facing health treatment or screening decisions. Cochrane Database Syst Rev. 2009;(3):CD001431.

117. Cox K, Stevenson F, Britten N, DundarY. A systematic review of communication between patients and healthcare professionals about medicine taking and prescribing. London: Medicines Partnership, 2004.

118. Ioannidis JP, Lau J. Evidence on interventions to reduce medical errors: an overview and recommendations for future research. J Gen Intern Med. 2001;16:325-334.

119. Raynor DK, Blenkinsopp A, Knapp P, et al. A systematic review of quantitative and qualitative research on the role and effectiveness of written information available to patients about individual medicines. Health Technol Assess. 2007;11:iii, 1-160.

120. Heneghan CJ, Glasziou P, Perera R. Reminder packaging for improving adherence to self-administered long-term medications. Cochrane Database Syst Rev. 2006;1:CD005025.

121. Sheridan SL, Viera AJ, Krantz MJ, et al; for Cardiovascular Health Intervention Research and Translation Network Work Group on Global Coronary Heart Disease Risk. The effect of giving global coronary risk information to adults: a systematic review. Arch Intern Med. 2010;170:230-239. 
122. Wagner EH, Austin BT, von Korff M. Organizing care for patients with chronic illness. Milbank Q. 1996;74:511-543.

123. Institute of Medicine. Crossing the Quality Chasm: A New Health System for the 21st Century. Washington, DC: National Academy Press, 2001

124. Kane RL, Priester R, Totten AM. Meeting the Challenge of Chronic Illness. Baltimore, MD: Johns Hopkins University Press, 2005.

125. Nutbeam D. The evolving concept of health literacy. Soc Sci Med. 2008;67:2072-2078.

126. Wills J. Health literacy: new packaging for health education or radical movement? Int J Pub Health. 2009;54:3-4.

127. Nielsen-Bohlman L, Panzer A, Kindig D, editors. Health Literacy: A Prescription to End Confusion. Washington, DC: National Academies Press, 2004.

128. Williams MV, Baker DW, Honig EG, et al. Inadequate literacy is a barrier to asthma knowledge and self-care. Chest. 1998;114: $1008-1015$

129. Ishikawa H, Takeuchi T, Yano E. Measuring functional, communicative, and critical health literacy among diabetic patients, Diabetes Care. 2008;31:874-879.

130. Wolf M, Davis T, Osborn C, Skripkauskas S, Bennett C, Makoul G. Literacy, self-efficacy, and HIV medication adherence. Patient Educ Couns. 2007;65:253-260.

131. von Wagner C, Semmler C, Good A, Wardle J. Health literacy and self-efficacy for participating in colorectal cancer screening: the role of information processing. Patient Educ Couns. 2009;75: 352-357.

132. Dewalt DA, Berkman ND, Sheridan S, Lohr KN, Pignone MP. Literacy and health outcomes: systematic review of the literature. J Gen Int Med. 2004;19:128-139.

133. DeWalt DA, Pignone MP. Reading is fundamental. The relationship between literacy and health. Arch Intern Med. 2005;165: 1943-1944.

134. Adams RJ, Appleton SL, Hill CL, Dodd M, Findlay C, Wilson DH. Risks associated with low functional health literacy in an Australian population. Med J Aust. 2009;191:530-534.

135. Australian Bureau of Statistics. Adult Literacy and Life Skills Survey, Summary Results, Australia 2006. cat. no. 4228.0. Canberra, Australia: Australian Bureau of Statistics, 2008.

136. Nutbeam D. Building health literacy in Australia. Med J Aust. 2009;191:525-526.

137. Girgerenzer G. Collective statistical illiteracy: a cross-cultural comparison with probabilistic national samples. Comment on "Statistical numeracy for health". Arch Intern Med. 2010;170:468.

138. Galesic M, Garcia-Retamero R. Statistical numeracy for health: a crosscultural comparison with probabilistic national samples. Arch Intern Med. 2010;170:462-468.

139. Centre for Labour and Social Policy Studies (BASS) Economic Aspects of Health Literacy. Concept paper. Canberra, Australia: Commissioned by the Federal Office of Public Health, 2006.

140. Pignone M, DeWalt DA, Sheridan S, Berkman N, Lohr KN. Interventions to improve health outcomes for patients with low literacy. A systematic review. J Gen Intern Med. 2005;20:185-192.

141. Clement S, Ibrahim S, Crichton N, Wolf M, Rowlands G. Complex interventions to improve the health of people with limited literacy: a systematic review. Patient Educ Couns. 2009;75: 340-351.

142. Katz MG, Jacobson TA, Veledar E, Kripalani S. Patient literacy and question-asking behavior during the medical encounter: a mixedmethods analysis. $J$ Gen Intern Med. 2007;22:782-786.

143. Smith SK, Trevena L, Nutbeam D, Barratt A, McCaffery KJ. Information needs and preferences of low and high literacy consumers for decisions about colorectal cancer screening: utilizing a linguistic model. Health Expect. 2008;11:123-136.

144. Rutten LJ, Squiers L, Hesse B. Cancer-related information seeking: hints from the 2003 Health Information National Trends Survey (HINTS). J Health Commun. 2006;11:147-156.
145. Dolan NC, Ferreira MR, Davis TC, et al. Colorectal cancer screening knowledge, attitudes, and beliefs among veterans: does literacy make a difference? J Clin Oncol. 2004;22:2617-2622.

146. Huizinga MM, Carlisle AJ, Cavanaugh KL, et al. Literacy, numeracy, and portion-size estimation skills. Am J Prev Med. 2009;36(4):324-328.

147. Peerson A, Saunders M. Health literacy revisited: what do we mean and why does it matter? Health Promot Int. 2009;24:285-296.

148. Rubinelli S, Schulz PJ, Nakamoto K. Health literacy beyond knowledge and behaviour: letting the patient be a patient. Int J Public Health . 2009;54:307-311.

149. Baker DW. The meaning and the measure of health literacy. $J$ Gen Intern Med. 2006;21:878-883.

150. Zarcodoolas C, Pleasant A, Greer DS. Understanding health literacy: an expanded model. Health Promot Int. 2005;20:195-203.

151. Kickbusch IS. Health literacy: addressing the health and education divide. Health Promot Int. 2001;16:289-297.

152. Bernhardt JM, Brownfield ED, Parker RM. Understanding health literacy. In: Schwartzberg JG, VanGeest J, Wang C, editors. Understanding Health Literacy: Implications for medicine and public health Chicago, IL: AMA Press, 2005.

153. Hibbard JH, Stockard J, Mahoney ER, et al. Development of the patient activation measure (PAM): conceptualizing and measuring activation in patients and consumers. Health Serv Res. 2004;39(4 Pt 1):1005-1026.

154. Hibbard JH, Mahoney E. Toward a theory of patient and consumer activation. Patient Educ Couns. 2010;78:377-381.

155. Kane RL. What can improve chronic disease care? JAm Geriatr Soc. 2009;57:2338-2345.

156. Kickbusch I. Thinker in Residence Interim Report. Adelaide, Australia: South Australian Government; 2007

157. Adams RJ, Stocks N, Wilson DH, et al. Health Literacy - a new concept for general practice? Aust Fam Phys. 2009;38:144-147.

158. Roter D, Frankel RM, Hall J, Sluyter D. The expression of emotion through non-verbal behaviour in medical visits mechanisms and outcomes. J Gen Intern Med. 2006;21:S28-S34.

159. Roter D, Stewart M, Putnam SM, et al. Communicating patterns of primary care physicians. JAMA. 1997;227:350-356.

160. Hall JA, Roter DL, Katz NR. Meta-analysis of correlates of provider behaviour in medical encounters. Med Care. 1988;26:657-675.

161. Consumer Assessment of Healthcare Providers and Systems (CAPHS). About the CAHPS Item Set for Addressing Health Literacy. Document No. 1311. Washington, DC: Agency for Healthcare Research and Quality, 2009.

162. Moore PM, Wilkinson SSM, Rivera Mercado S. Communication skills training for health care professionals working with cancer patients, their families and/or carers. Cochrane Database Syst Rev. 2004;(2):CD003751.

163. Griffin SJ, Kinmonth AL, Veltman MW, Gillard S, Grant J, Stewart M. Effect on health-related outcomes of interventions to alter the interaction between patients and practitioners: a systematic review of trials Ann Fam Med. 2004;2:595-608.

164. Gysels M, Richardson A, Higginson IJ. Communication training for health professionals who care for patients with cancer: a systematic review of effectiveness. Support Care Cancer. 2004;12: 692-700.

165. Hulsman RL, Ros WJ, Winnubst JA, Bensing JM. Teaching clinically experienced physicians communication skills. A review of evaluation studies. Med Educ. 1999;33:655-668.

166. Lewin SA, Skea ZC, Entwistle V, Zwarenstein M, Dick J. Interventions for providers to promote a patient-centred approach in clinical consultations. Cochrane Database Syst Rev. 2001;4:CD003267.

167. Stevenson FA, Cox K, Britten N, Dundar Y. A systematic review of the research on communication between patients and health care professionals about medicines: the consequences for concordance. Health Expect. 2004;7:235-245.

168. McKinstry B, Ashcroft RE, Car J, Freeman GK, Sheikh A. Interventions for improving patients' trust in doctors and groups of doctors. Cochrane Database Syst Rev. 2006;3:CD004134. 
169. Mead N, Bower P. Patient-centred consultations and outcomes in primary care: a review of the literature. Patient Educ Couns. 2002; 48:51-61.

170. RTI International. Literacy and Health Outcomes. Rockville, MD: Agency for Healthcare Research and Quality; 2004.

171. Glazier RH, Bajcar J, Kennie NR, Willson K. A systematic review of interventions to improve diabetes care in socially disadvantaged populations. Diabetes Care. 2006;29:1675-1688.

172. Marcus AC, Crane LA. A review of cervical cancer screening intervention research: implications for public health programs and future research. Prev Med. 1998;27:13-31.

173. Prochaska JO. Systems of Psychotherapy: A Transtheoretical Analysis. Homewood, IL: Dorsey Press, 1979.

174. Prochaska JO, DiClemente CC. Transtheoretical therapy: toward a more integrative model of change. Psychotherapy. 1982;19:276-288.

175. Hibbard JH, Mahoney ER, Stockard J, Tusler M. Development and testing of a short form of the patient activation measure. Health Serv Res. 2005;40:1918-1930.

176. Goroll AH, Berenson RA, Schoenbaum SC, et al. Fundamental reform of payment for adult primary care: comprehensive payment for comprehensive care. J Gen Intern Med. 2007;22:410-415.

177. Coorey P. Rudd offers diabetes sweetener. Sydney Morning Herald, 2010 Apr 1. Available from: http:/www.smh.com.au/national/ruddoffers-diabetes-sweet ener-20100331-rewo.html. Accessed Sept 10, 2010.

178. Kelly PA, Haidet P. Physician overestimation of patient literacy: a potential source of health care disparities. Patient Educ Couns. 2007;66:119-122.
179. Weiss BD. Health Literacy and Patient Safety: Help Patients Understand: A Manual for Clinicians. 2nd ed. Chicago, IL: American Medical Association Foundation and American Medical Association; 2007.

180. Grunwald M. How Obama is using the science of change. Time, 2009 April 2. Available from: http://www.time.com/time/magazine/ article/ 0,9171,1889153,00.html. Accessed Sept 10, 2010.

181. Thaler RH, Sunstein CR. Nudge: Improving Decisions About Health, Wealth, and Happiness. New Haven: Yale University Press, 2008.

182. Loewenstein G, Brennan T, Volpp KG. Asymmetric paternalism to improve health behaviors. JAMA. 2007;298(20):2415-2417.

183. Volpp KG, Loewenstein G, Troxel AB, et al. A test of financial incentives to improve warfarin adherence. BMC Health Serv Res. 2008;8:272.

184. Volpp KG, John LK, Troxel AB, Norton L, Fassbender J, Loewenstein G. Financial incentive-based approaches for weight loss: a randomized trial. JAMA. 2008;300:2631-2637.

185. Glasgow RE, Lichtenstein E, Marcus AC. Why don't we see more translation of health promotion research to practice? Rethinking the efficacy to effectiveness transition. Am J Public Health. 2003;93:1261-1267.

186. Glasgow RE, Klesges LM, Dzewaltowski DA, Estabrooks PA, Vogt TM. Evaluating the impact of health promotion programs: using the RE-AIM framework to form summary measures for decision making involving complex issues. Health Educ Res. 2006;21:688-694.

187. Glasgow RE, Nelson CC, Strycker LA, King DK. Using RE-AIM metrics to evaluate diabetes self-management support interventions. Am J Prev Med. 2006;30:67-73.

\section{Publish your work in this journal}

Risk Management and Healthcare Policy is an international, peerreviewed, open access journal focusing on all aspects of public health, policy, and preventative measures to promote good health and improve morbidity and mortality in the population. The journal welcomes submitted papers covering original research, basic science, clinical \& epidemio-

\section{Dovepress}

logical studies, reviews and evaluations, guidelines, expert opinion and commentary, case reports and extended reports. The manuscript management system is completely online and includes a very quick and fair peerreview system, which is all easy to use. Visit http://www.dovepress.com/ testimonials.php to read real quotes from published authors. 